\title{
Microstructures and high-temperature self-lubricating wear- resistance mechanisms of graphene-modified WC-12Co coatings
}

\author{
Haoliang TIAN*, Changliang WANG, Mengqiu GUO, Yongjing CUI, Junguo GAO, Zhihui TANG \\ Aviation Key Laboratory of Science and Technology on Advanced Corrosion and Protection for Aviation Material Beijing, Aero Engine \\ Corporation of China Beijing Institute of Aeronautical Materials, Beijing 100095, China \\ Received: 03 August 2019 / Revised: 14 October 2019 / Accepted: 03 December 2019 \\ (C) The author(s) 2019.
}

\begin{abstract}
To reduce the friction coefficient of cobalt-cemented tungsten carbide (WC-12Co) wear-resistant coatings, graphene was compounded into WC-12Co powder via wet ball milling and spray granulation. Selflubricating and wear-resistant graphene coatings were prepared via detonation gun spraying. The presence, morphologies, and phase compositions of graphene in the powders and coatings that are obtained through different powder preparation processes were analyzed. The analysis was performed using the following technologies: energy-dispersive X-ray-spectroscopy (EDXS), scanning electron microscopy (SEM), transmission electron microscopy (TEM), and Raman spectroscopy. The mechanical properties of the coatings were studied using a microhardness tester and a universal drawing machine. The friction and wear properties of the coatings were studied using an SRV-4 friction and wear tester. The results showed that the graphene content in the WC-12Co coating modified with graphene was higher than that without modification; graphene was embedded in the structure in a transparent and thin-layer state. The adhesive strength of this coating at approximately $25{ }^{\circ} \mathrm{C}$ was approximately $60.33 \mathrm{MPa}$, and the hardness was approximately $984 \mathrm{HV}_{0.3}$. After high-temperature treatment, the adhesive strength and hardness of the graphene oxide (GO)/WC-12Co coating decreased slightly (the lowest adhesive strength of $53.16 \mathrm{MPa}$ was observed after treatment at $400{ }^{\circ} \mathrm{C}$, and the lowest hardness of approximately $837 \mathrm{HV}_{0.3}$ was observed after treatment at $300{ }^{\circ} \mathrm{C}$ ). Compared to the friction coefficient (0.6) of the WC-12Co coating obtained at room temperature, the friction coefficient of the GO/WC-12Co coating was decreased by approximately $50 \%$ of that value. The graphene-modified coating was continuously exposed to the wear tracks on the surface of the contacting materials during friction, and a lubricating film was formed in the microareas in which the wear tracks were present. The coating exhibited improved self-lubricating and wear-resistant effects compared to the unmodified WC-12Co coating. The results of this study demonstrated that graphene could be effective in self-lubrication and wear-reduction in a temperature range of $100-200{ }^{\circ} \mathrm{C}$, as a friction coefficient of 0.3 was maintained.
\end{abstract}

Keywords: graphene; wear-resistant coating; detonation gun spraying; self-lubricating wear-resistance mechanism; high-temperature friction

\section{Introduction}

In 2004, Novoselov et al. [1] used adhesive tape to repeatedly adhere to and peel away from highly oriented pyrolytic graphite (HOPG) to prepare single layers of graphene. In the past five years, motivated by the excellent mechanical properties of graphene as the basic structural unit of solid carbonaceous

* Corresponding author: Haoliang TIAN, E-mail: haoliangtian@163.com 
lubricants, the tribological properties of graphene and the development of graphene-based composite lubricating materials have become a focus of research in the field of tribology [2-4]. As antiadhesive and antifriction protective films for micro/nanodevices based on various materials, single-layer, three-layer, and multilayer graphene-based nanolubricating films significantly reduce the friction coefficients and improve the durability of the surfaces of these devices $[5,6]$. As an additive to both ionic liquid- and waterbased lubricants, graphene can form adsorption films, and the transfer film formed at a friction interface can prevent direct contact between the surfaces of the friction pair, thereby significantly improving the bearing load of the lubricant and the antiwear performance of the friction pair [7]. As a filler for materials such as polymers and ceramics, graphene can significantly improve the mechanical properties of the matrix material, reduce the friction coefficient, and greatly improve the antiwear properties of such a polymer matrix through the formation of a continuous transfer film with self-lubricating and strong binding properties [8-10].

The current solid lubricants used in thermal spray coatings include soft metals ( $\mathrm{Au}, \mathrm{Ag}$, etc.), fluorides $\left(\mathrm{LiF}_{2}, \mathrm{CaF}_{2}\right.$, etc.), disulfides $\left(\mathrm{MoS}_{2}, \mathrm{WS}_{2}\right.$, etc. $)$, and oxides $\left(\mathrm{Zr}_{2} \mathrm{O}_{3}, \mathrm{Cr}_{2} \mathrm{O}_{3}\right.$, etc.). Many studies on the application of such lubricants as lubricating phases in coatings have been performed using currently available technologies. However, these additives all have certain limitations; for example, a sulfide-based lubricating phase that is added to a coating undergoes oxidation as the temperature increases during friction, which results in a serious decrease in the tribological properties, especially in humid environments. In addition, although fluorides composed of alkaline earth metals and rare metals have self-lubricating properties at high temperatures, these materials are brittle at low temperatures due to their poor tribological properties [11, 12].

Applications of graphene as a nanolubricating additive in thermal spraying technology have been presented in the studies cited above. However, in order to use graphene in a thermal spray coating, it needs to achieve good compatibility and mixing with the coating material; moreover, graphene needs to be of a suitable form, which can be effectively retained in the coating [13]. To develop self-lubricating and antiwear applications of graphene in cobalt-cemented tungsten carbide (WC-12Co) wear-resistant coatings, the spray granulation technique was used in this study to mix graphene with WC-12Co powder and to prepare a graphene oxide (GO)/WC-12Co coating (i.e., a graphene-modified self-lubricating wear-resistant coating) via detonation gun (D-gun) spraying. We studied the basic properties of the various obtained powders and coatings, focusing on their influence on the self-lubricating wear-resistance characteristics and mechanisms of graphene during a high-temperature wear process (over a temperature range from room temperature to $550{ }^{\circ} \mathrm{C}$ ).

\section{Experimental}

\subsection{Materials and reagents}

The graphene used in the experiments was enhancedtype graphene (SE1430) from the Sixth Element (Changzhou) Materials Technology Co., Ltd., China, and its microscopic morphology is shown in Fig. 1(a). Graphene nanosheets can be observed in Fig. 1. The physical properties of the graphene are given in Table 1. The selected powder materials used for spraying were tungsten carbide (WC) powder and cobalt (Co) alloy powder, produced by Beijing United Coating Technologies Co., Ltd., China. The powder particle sizes were $<5 \mu \mathrm{m}$, the purities were $\geqslant 99.5 \%$, and WC and Co powder microscopic appearances are shown in Figs. 1(b) and 1(c), respectively.

\subsection{GO/WC-12Co composite powder preparation process}

First, $88 w t \%$ WC powder, $12 \mathrm{wt} \%$ Co powder, and $0.1 \mathrm{wt} \%$ graphene were weighed. Zirconia balls with a diameter of $10 \mathrm{~mm}$ were used to ball mill WC-12Co and graphene in an anhydrous ethanol medium for $10 \mathrm{~h}$ at a ball mill rotation speed of $3 \mathrm{rpm}$. The ballmilled mixed powder was then ultrasonicated in the same liquid medium for $2 \mathrm{~h}$. After drying at $40^{\circ} \mathrm{C}$ for $2 \mathrm{~h}$, the sample was sieved to obtain a raw composite graphene/WC/Co spray powder material with a particle size of 3-6 $\mu \mathrm{m}$. About $15 \mathrm{wt} \%$ polyvinyl alcohol binder 

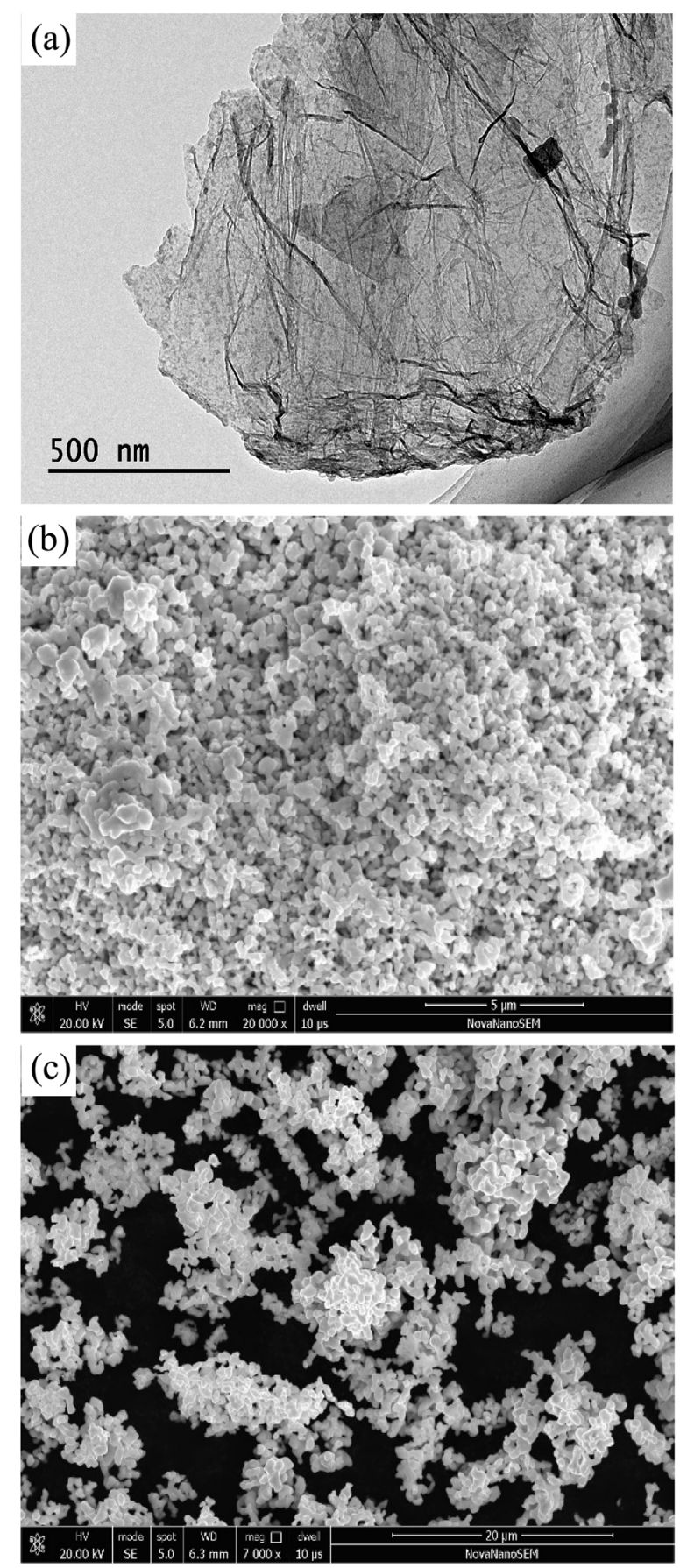

Fig. 1 SEM images of the raw materials: (a) graphene, (b) WC, and (c) Co.

Table 1 Physical properties of the graphene used for testing.

\begin{tabular}{cccccc}
\hline $\begin{array}{c}\text { Density } \\
\left(\mathrm{g} / \mathrm{cm}^{3}\right)\end{array}$ & $\begin{array}{c}\text { Surface area } \\
\left(>\mathrm{m}^{2} / \mathrm{g}\right)\end{array}$ & $\begin{array}{c}\text { Water mass } \\
\text { fraction }(\%)\end{array}$ & $\begin{array}{c}\text { D50 } \\
(\mu \mathrm{m})\end{array}$ & $\begin{array}{c}\mathrm{C} \\
(\mathrm{wt} \%)\end{array}$ & $\begin{array}{c}\mathrm{O} \\
(\mathrm{wt} \%)\end{array}$ \\
\hline$<0.1$ & $180-280$ & $<4$ & $<10$ & $75 \pm 5$ & $16 \pm 3$ \\
\hline
\end{tabular}

was added and mixed into the powder by stirring. The sample was then heated to $120^{\circ} \mathrm{C}$ to obtain a viscous mixed slurry. The slurry was sprayed at a certain speed (80-120 atm) in a furnace atomizer and cooled under a protective argon atmosphere. Finally, the composite GO/WC-12Co powder material was collected and sieved to yield a particle size of approximately 15 to $45 \mu \mathrm{m}$.

\subsection{Coating preparation technique}

The coatings were prepared using a Russian OB D-gun spraying system. Acetylene and propane were the fuel gases, oxygen was the combustion gas, and nitrogen was used as the carrier gas for powder feeding. The parameters of the spraying process are shown in Table 2. The sprayed substrate material was 304 stainless steel, and the metallographic sample size was $100 \mathrm{~mm} \times 20 \mathrm{~mm} \times 2 \mathrm{~mm}$. Before spraying, the surface of the substrate was cleaned with acetone or ethanol to remove oil and contaminants, followed by roughening treatment via sandblasting. For sandblasting, 46-mesh white corundum was used with a blasting pressure of $0.5-0.6 \mathrm{MPa}$. The prepared coating thickness was approximately $200 \mu \mathrm{m}$.

\subsection{Characterization methods}

The powder morphology, particle size, and crosssectional coating layer morphology were analyzed using scanning electron microscopy (SEM, Quanta 600, FEI, USA). The chemical composition of the coating was analyzed via energy-dispersive X-ray spectroscopy (EDXS), and the porosity of the coating was measured with porosity analysis software. The samples were also subjected to Raman spectroscopy using a laser confocal Raman spectrometer (LabRAM HR800, He-Ne laser, $632.8 \mathrm{~nm}$ wavelength). The morphologies of the graphene and mixed powders were analyzed using transmission electron microscopy (TEM, JEM-2100, JEOL, Japan). The microhardness of the coatings was tested using a Struers Duramin microhardness tester (AMH43, Japan) with a load of $300 \mathrm{~g}$, a loading time

Table 2 Spraying process parameters.

\begin{tabular}{ccc}
\hline $\mathrm{O}_{2} / \mathrm{C}_{2} \mathrm{H}_{2}$ & $\begin{array}{c}\mathrm{O}_{2} / \mathrm{C}_{2} \mathrm{H}_{2} \text { in-gun } \\
\text { ratio (\%) }\end{array}$ & Frequency (shot/s) \\
\hline 1.2 & 50 & 4 \\
\hline \hline Powder feed rate $(\mathrm{g} / \mathrm{s})$ & Distance (mm) & Barrel diameter $(\mathrm{mm})$ \\
\hline 0.15 & 240 & 20 \\
\hline
\end{tabular}


of $15 \mathrm{~s}$, and 10 test points for each sample. The adhesive strength of each coating with the substrate was tested using an Instron 5882 universal testing machine in accordance with China Aviation Industry Standard HB5143-1996. Pull-off tests were performed using an electronic universal testing machine (Zwick/Roell Z050, Germany). Each of the aforementioned tests were carried out three times for each sample, and the average values of these properties were calculated. The friction and wear characteristics of the coatings were determined on an SRV-4 reciprocating friction and wear tester (Optimol, Germany) using ball-tosurface contact. The upper sample was a hard WC-steel alloy ball with a diameter of $\Phi=8 \mathrm{~mm}$ and a hardness of $\geqslant 60 \mathrm{HRC}$. The lower sample size was $\varnothing=24 \mathrm{~mm} \times$ $7.8 \mathrm{~mm}$, with the surface of the coating polished to a final coating thickness of approximately $0.3 \mathrm{~mm}$ and a surface roughness $(R a)$ of 0.4 or less. The testing parameters included a wear time of $30 \mathrm{~min}$, a frequency of $20 \mathrm{~Hz}$, a displacement amplitude $(D)$ of $1 \mathrm{~mm}$, a normal load of $50 \mathrm{~N}$, and these tests were carried out at temperatures of 200,300 , and $400{ }^{\circ} \mathrm{C}$.

\section{Results}

\subsection{GO/WC-12Co spray materials}

Figures 2(a) and 2(b) show the morphologies of the WC-12Co powders with and without graphene modification, respectively. The unmodified powder obtained after ball milling and spray granulation is spherical. The particles are dense and uniform with a size of approximately 25-45 $\mu \mathrm{m}$. Figure 2(b) shows the morphology of the graphene-modified WC-12Co powder. The particles of the composite powder prepared via ball milling and spray granulation are also spherical. These particles have high dimensional integrity and uniform sizes. The sphericity and particle size are basically the same as those of unmodified WC-12Co. Additionally, a transparent thin layer of graphene is adhered to the particle surface or is tightly embedded in the inner walls in crevices of the particle (GO is indicated by the arrows in Fig. 2). The graphene groups are not agglomerated, and graphene adheres to the surface of each powder particle. This observation shows that the continuous mechanical interaction of the graphene and WC-12Co particles
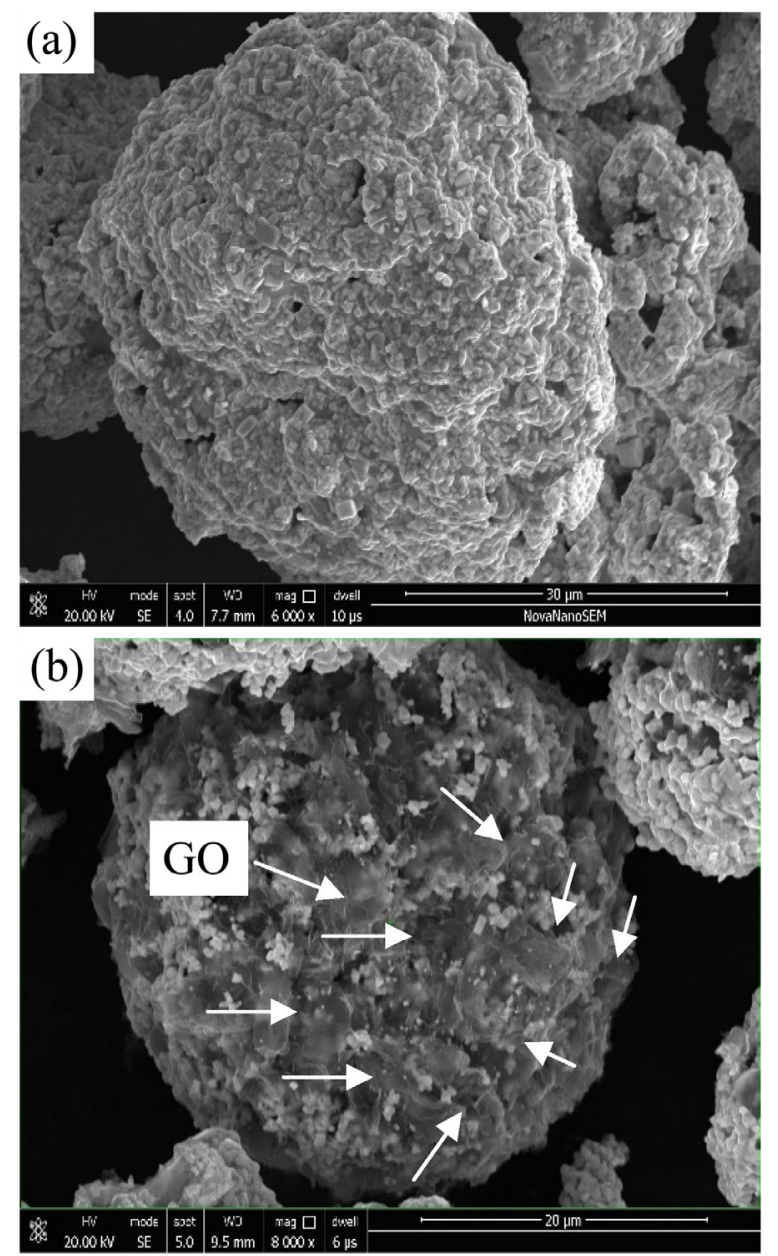

Fig. 2 SEM morphologies of the spray powders: (a) $\mathrm{WC}-12 \mathrm{Co}$ and (b) $\mathrm{GO} / \mathrm{WC}-12 \mathrm{Co}$.

during the ball milling process enables effective mixing, and spray granulation enables the inner coating and surface embedding of graphene on the spherical powder particles. This can ensure the effective deposition of graphene during spraying and greatly enhance the self-lubricating effect of the graphene in the resulting coating.

Figure 3(a) shows a local high-magnification morphological analysis of the graphene-modified WC-12Co powder, from which it can be seen that a thin, transparent graphene layer with high dimensional integrity completely covers the particle surface (GO is indicated by the arrows). The adhesion ratio and distribution are relatively uniform on the surface of each particle, indicating that spray granulation does not cause the graphene to separate from the powder after the graphene has adhered to the particle surfaces via polyvinyl alcohol. Therefore, the initial graphene 


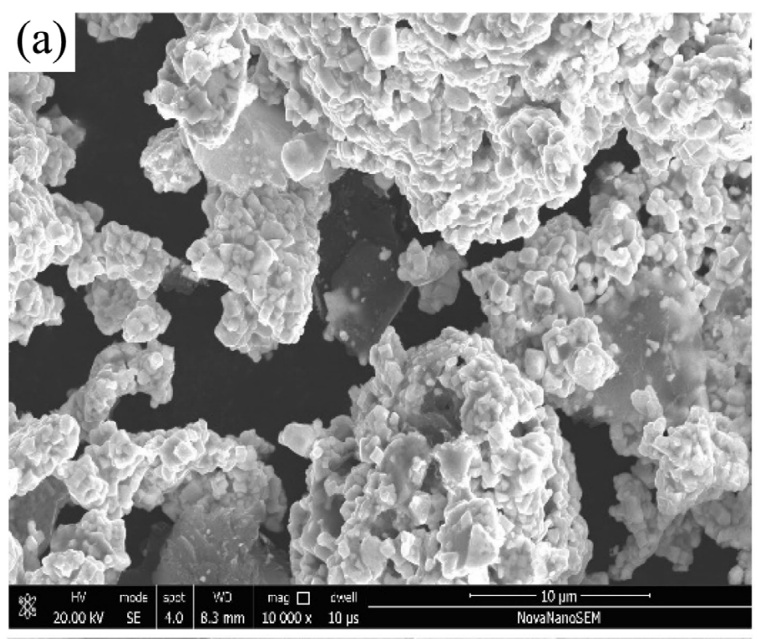

(a)

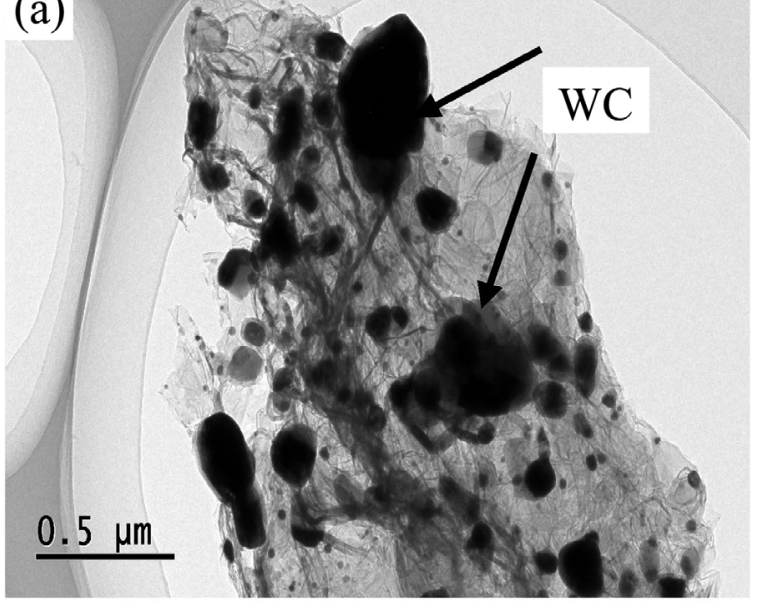

Fig. 3 Morphology of graphene in the composite spray powder: (a) SEM image of the grapheme and (b) TEM image of the graphene.

content and adhesion on the particle surfaces are effectively retained. The TEM analysis in Fig. 3(b) shows black particles attached to the surface of the transparent graphene or wrapped in the graphene film. According to a composition analysis, the mass percentage of tungsten in these black particles is $84.23 \%$, and the mass percentage of carbon is $10.28 \%$, indicating that these particles are indeed WC. This result occurred because of the use of 10-mm-diameter zirconia balls in the wet ball milling process to continuously grind graphene, $\mathrm{WC}$, and Co particles in an ethanol medium. Mechanical grinding can promote the adhesion of graphene to WC and Co, causing the graphene to be loaded with small WC particles on its surface and thereby increasing the compatibility of the graphene with the WC powder. This phenomenon can largely avoid the dissipation of the lightweight graphene in the high-speed spray beam, thereby improving the loading ratio of the graphene in the final coating.

\subsection{Microstructure of the coating}

Figure 4(a) shows the cross-sectional microstructure of the WC-12Co coating without graphene. The coating microstructure is dense and tightly bonded to the matrix interface with a porosity of $1.37 \%$. Figure $4(\mathrm{~b})$ shows the cross-sectional morphology of the graphene/ WC-12Co coating. The cross-section of this coating is dense, uniform, and free of cracks, with a porosity of $1.41 \%$. No unmelted particles are found inside the coating. No obvious pores or microcracks are found at the bonding interface, indicating tight bonding to the matrix. This observation indicates that the completeness, particle size uniformity, and fluidity of the spherical powders obtained via spray granulation are very beneficial for the melt binding of the powder during the spraying process, enabling the formation of a dense coating [13]. Figure 4(b) shows the fracture morphology of the graphene/WC-12Co coating. A transparent sheet of graphene with a size of approximately $10 \mu \mathrm{m}$ is shown to be embedded inside of the microstructure, and this graphene sheet still has a transparent, thin-layered structure.

This observation indicates that the state of graphene is not affected by the spraying process. Spray granulation ensures close adhesion of the graphene to the surfaces of the powder particles, which, in turn, ensures that the molten particles can carry the graphene for deposition at a high transient speed during the spraying process, thereby allowing the coating to be formed while preserving the maximum graphene content and the original characteristics of the graphene. This outcome indicates that the ball milling treatment and the spray granulation compositing process together achieve uniform and high bonding adhesion between the graphene and the WC-12Co powder. D-gun spraying technology uses pulsed spot spraying. Molten spray particles carrying graphene strike the target surface instantaneously, thereby ensuring that the graphene is effectively retained inside of the coating [14]. This also serves to avoid the flow dissipation of lightweight graphene that is caused by the continuous high-speed particle beams found in other types of 

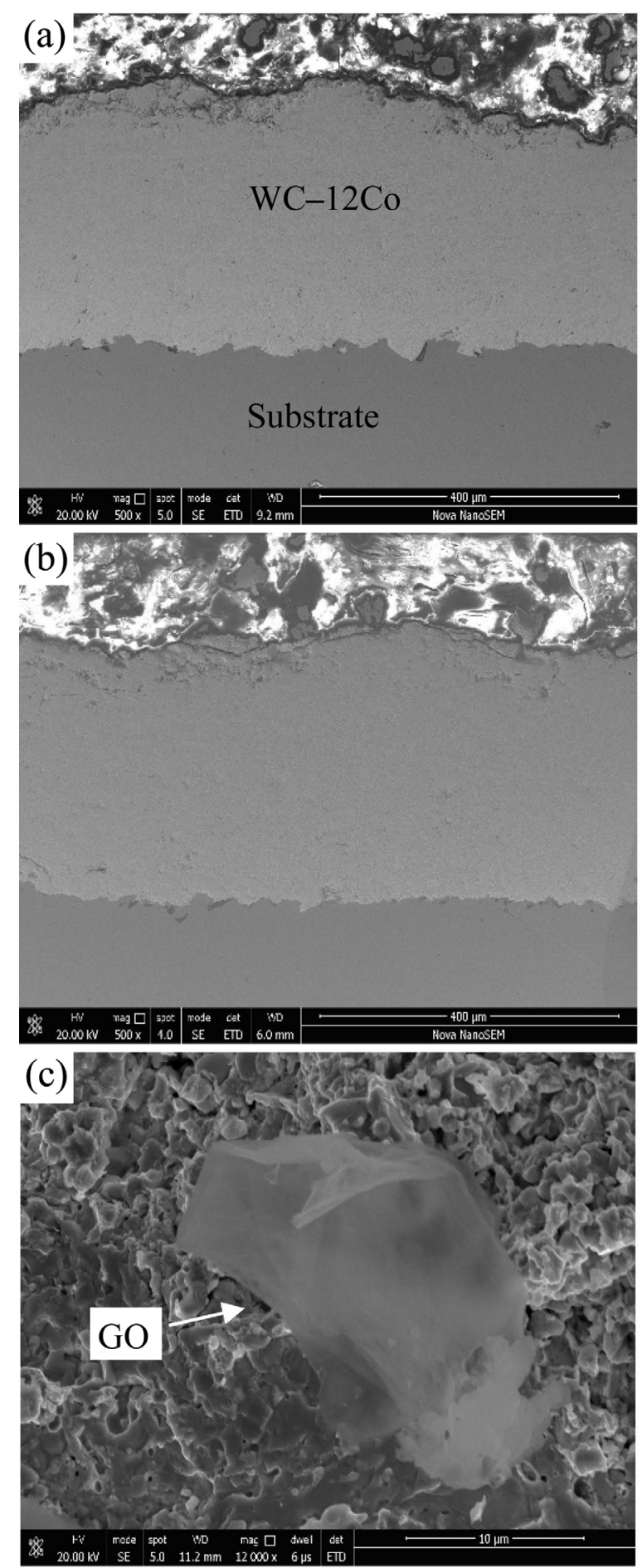

Fig. 4 Microstructural morphologies of the coatings: (a) cross section of the WC-12Co coating, (b) cross section of the $\mathrm{GO} / \mathrm{WC}-12 \mathrm{Co}$ coating, and (c) fracture morphology of the $\mathrm{GO} / \mathrm{WC}-12$ Co coating.

thermal spraying (supersonic flame spraying, plasma spraying, etc.). The graphene content inside the coating is high and the distribution is uniform, which makes the graphene in the coating more likely to form a lubricating film during friction and thus reduce the friction coefficient.

As seen from the selected area electron diffraction (SAED) analysis shown in Fig. 5(a), the graphene structure observed in the fracture exhibits a diffusely scattered amorphous ring along with peaks corresponding to a small amount of composited compound. This finding indicates that after spraying, the graphene substantially remains in its original form as an amorphous film and is composited with the WC $-12 \mathrm{Co}$ coating microstructure to a certain extent, as shown in Fig. 3(b). A TEM image of the edge of the graphene film layer is shown in Fig. 5(c). The graphene shows good integrity, wrinkles are clearly visible, and the graphene sheet consists of a few layers and has a transparent morphology. Figure 5(b) displays the Raman spectrum of the graphene film. The $G$ peak that appears near $1,580 \mathrm{~cm}^{-1}$, which arises from the first-order E2g in-plane phonon vibration, reflects the symmetry and order of the graphene. The larger the intensity ratio $\left(I_{\mathrm{D}} / I_{\mathrm{G}}\right)$ between the $\mathrm{D}$ and $\mathrm{G}$ peaks, the smaller the number of graphene layers; the more the number of graphene layers, the stronger the $\mathrm{sp}^{2}$ vibration of the carbon atoms and the stronger the $G$ peak. The D peak width of single-layer graphene is approximately $30 \mathrm{~cm}^{-1}$, while that of double-layer graphene is approximately $50 \mathrm{~cm}^{-1}$. Graphene materials with 3 or more layers have even wider peaks, but the difference is not significant [15]. Figure 5(b) shows that the $G$ peak is weak, and the width of the D peak is approximately $107 \mathrm{~cm}^{-1}$; this indicates that the graphene formed in this experiment consists of only a few layers. As shown in Fig. 1(c), the graphene film can be directly observed to contain approximately 7 to 10 layers.

\subsection{Mechanical property analysis}

Compared with the cross-sectional microstructure of the WC-12Co coating without graphene (Fig. 6(a)), the cross-sectional microstructure of the graphene-modified WC-12Co coating changes little after heat treatment at different temperatures (Figs. 6(b)-6(f)). A small number of pores exist at the coating interface after heat treatment at $300{ }^{\circ} \mathrm{C}$, while the other coatings are tightly bonded at the substrate interface. 

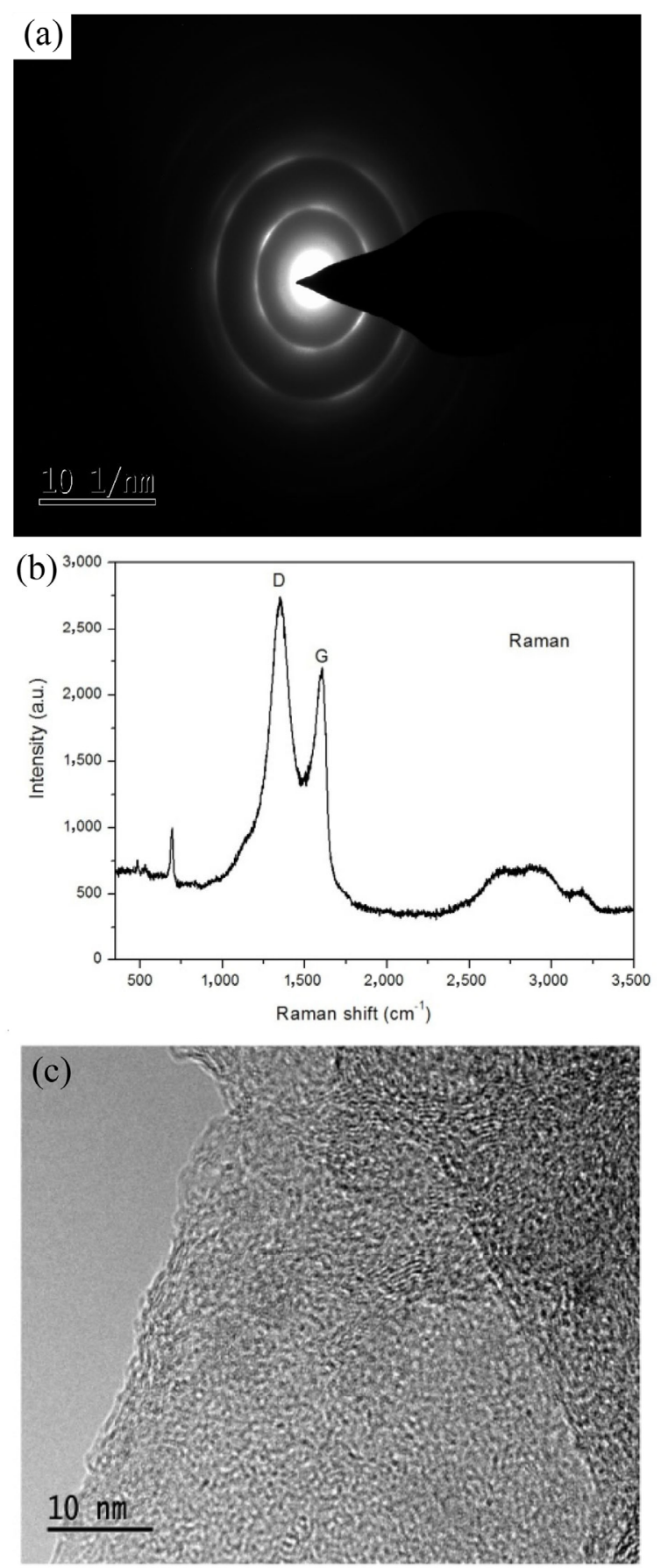

Fig. 5 Graphene microstructure and morphology in the coating cross section: (a) SAED analysis, (b) Raman spectroscopy analysis, and (c) TEM analysis.

Figure 7 presents a porosity analysis of the coatings obtained after different heat treatments, with porosity values of $1.37 \%$ (WC-12Co coating, room temperature), $1.41 \%$ (GO/WC-12Co coating, room temperature), $1.55 \%$ (GO/WC-12Co coating, $100{ }^{\circ} \mathrm{C}$ ), 1.57\% (GO/WC-12Co coating, $\left.200{ }^{\circ} \mathrm{C}\right), 1.86 \%$ (GO/WC-12Co coating, $\left.300{ }^{\circ} \mathrm{C}\right)$,

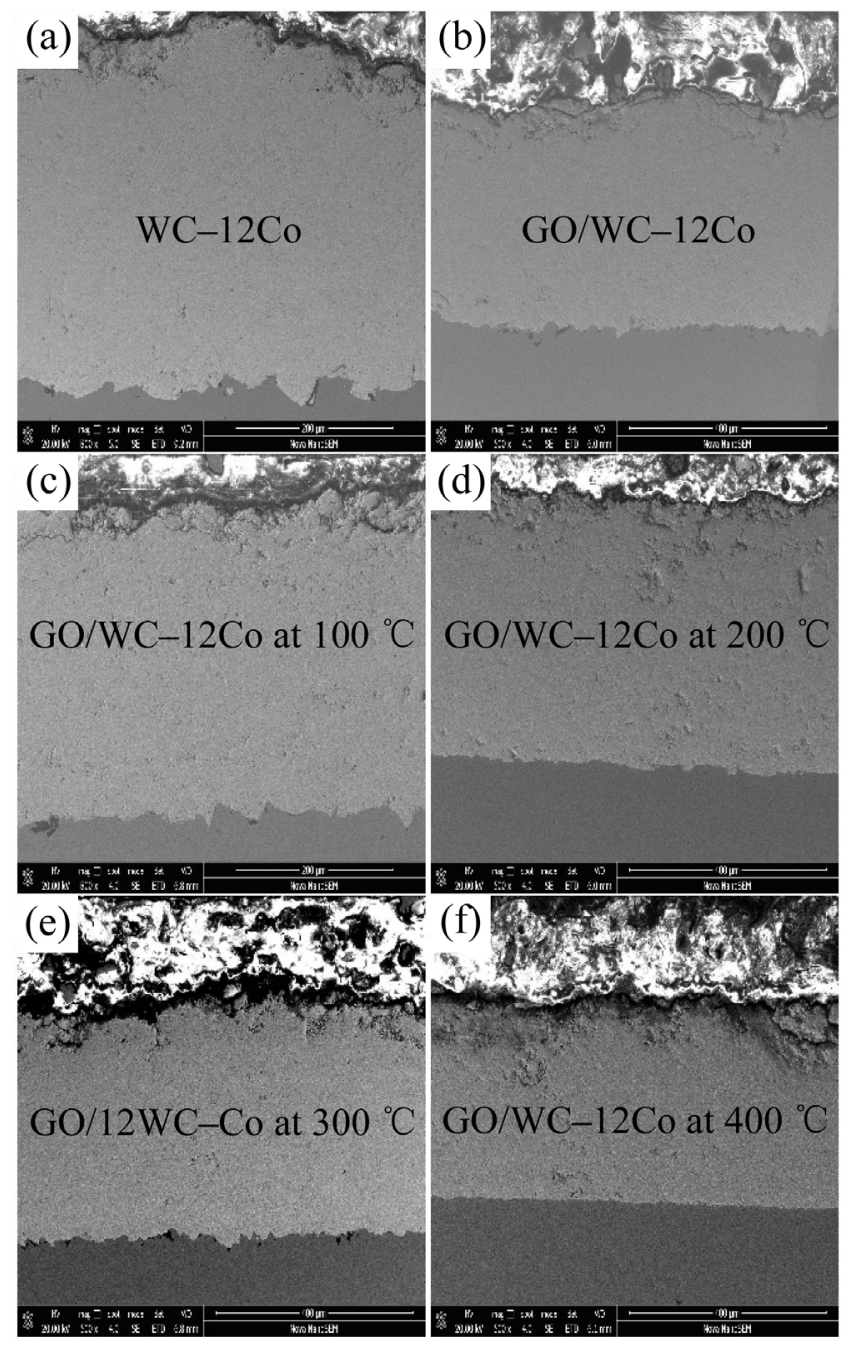

Fig. 6 Cross-sectional morphologies of the coatings obtained after different heat treatment processes.

and $1.88 \%$ (GO/WC-12Co coating, $\left.400{ }^{\circ} \mathrm{C}\right)$. As the heat treatment temperature increases, the porosity of the resulting GO/WC-12Co coating also increases slightly. As seen in Fig. 6, the structure of the GO/WC-12Co coating near the surface is loose, and tiny cracks and pores are visible. The reason for these cracks and pores is that the particle size of the powder is approximately 25-45 $\mu \mathrm{m}$ (Fig. 2), whereas for the preparation of a high-density coating, the D-gun spraying process requires more than $95 \%$ by weight of the overall powder to possess a particle size of $30-45 \mu \mathrm{m}$. In a powder form with a smaller particle size, the WC12Co composition is not uniform, and the binding of the Co and WC is poor. These phenomena reduce the overall fluidity and density of the powder, as well as the amount of powder delivered to the D-gun 


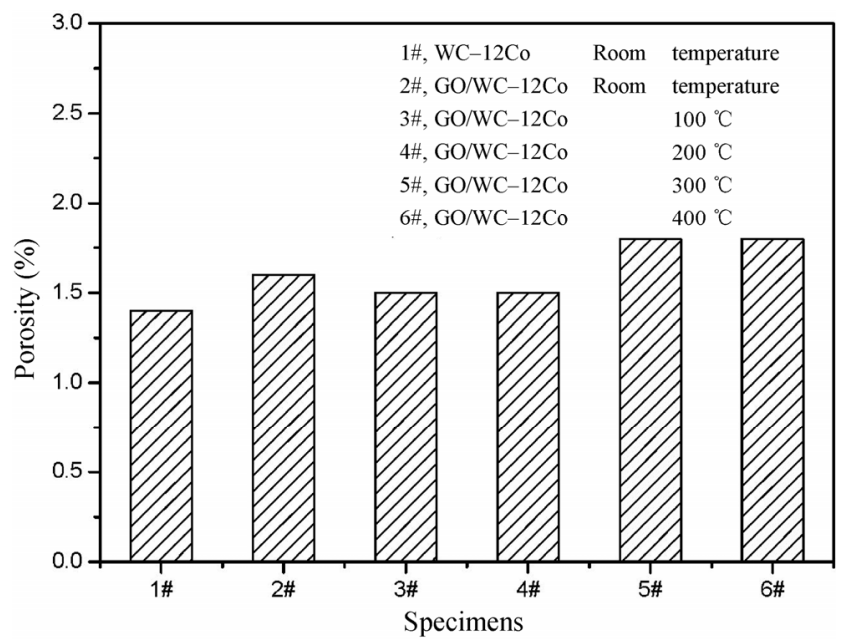

Fig. 7 Porosities of the coatings prepared via different heat treatment processes.

chamber during spraying. In addition, WC can easily decompose to produce $\mathrm{W}$ and $\mathrm{C}$ at $550{ }^{\circ} \mathrm{C}$. The instantaneous temperature in the detonation chamber is high $\left(1,500-2,200{ }^{\circ} \mathrm{C}\right)$ when WC is mixed with the high-temperature gas; therefore, the WC in the smallsized particles is easily decomposed at this high temperature, and only larger-sized powder particles (30-45 $\mu \mathrm{m})$ can be effectively deposited to form the coating [16]. In addition, under the high-speed (700$1,000 \mathrm{~m} / \mathrm{s}$ ) pulse detonation wave, the small-sized powder particles will be decomposed and dissipated. As a result, many pores are formed in the coating by the atmospheric oxidation of $\mathrm{C}$. Consequently, the microstructure near the surface of the coating becomes loose after high-temperature heat treatment because of the small-sized spray particles embedded in the surface.

Figure 8 shows the microhardness values of the coatings obtained after heat treatment at different temperatures; specifically, these values are $1,065 \mathrm{HV}_{0.3}$ (WC-12Co coating, room temperature), $984 \mathrm{HV}_{0.3}$ (GO/WC-12Co coating, room temperature), $934 \mathrm{HV}_{0.3}$ (GO/WC-12Co coating, $100^{\circ} \mathrm{C}$ ), $857 \mathrm{HV}_{0.3}$ (GO/WC-12Co coating, $\left.200{ }^{\circ} \mathrm{C}\right), 837 \mathrm{HV}_{0.3}$ (GO/WC-12Co coating, $\left.300{ }^{\circ} \mathrm{C}\right)$, and $866 \mathrm{HV}_{0.3}\left(\mathrm{GO} / \mathrm{WC}-12 \mathrm{Co}\right.$ coating, $\left.400{ }^{\circ} \mathrm{C}\right)$. As the heat treatment temperature increases, the hardness of the GO/WC-12Co coating slightly decreases, although the heat-treated coating does not undergo phase transformation at temperatures $<400{ }^{\circ} \mathrm{C}$. The main reason for this decrease in hardness results from

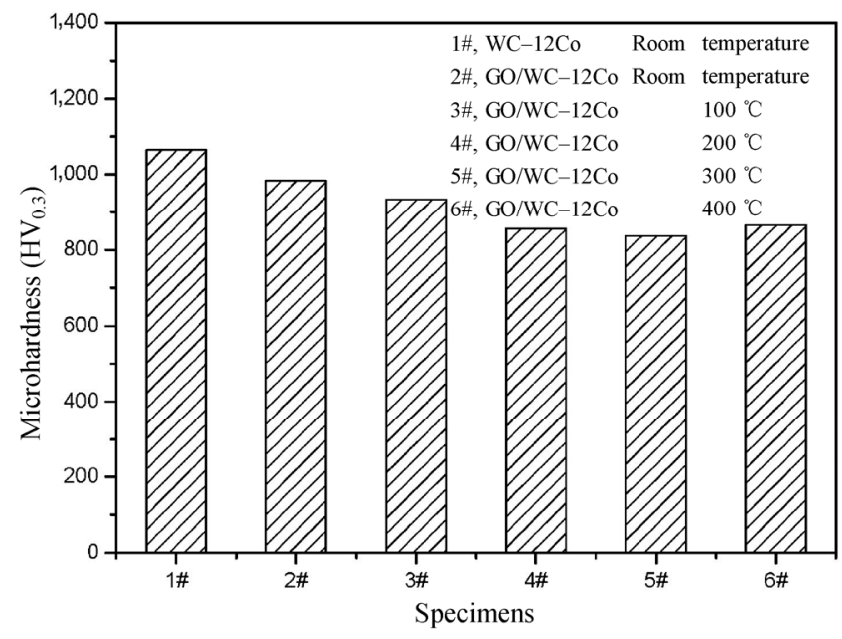

Fig. 8 Microhardness values of the coatings prepared via different heat treatment processes.

the porosity of the coating, which allows for nearby carbon or graphene that is not embedded in the WC-12Co coating structure to be oxidized, leading to a decrease in the coating density. However, as shown in Fig. 6, the overall cross-sectional structure of the coating is dense, and a loose structure exists only in the surface layer of the coating (to a depth of approximately $5 \mu \mathrm{m}$ ); thus, the decrease in density has little effect on the long-term applicability of the coating.

As shown in Fig. 9, the room-temperature adhesive strength of the WC-12Co coating without graphene is $63.52 \mathrm{MPa}$, and the room-temperature adhesive strength of the graphene-modified WC-12Co coating is $60.33 \mathrm{MPa}$. As mentioned previously, the spray granulation process can incorporate the light-weight graphene into the powder by coating the power particles with graphene, thereby preventing the graphene from being blown off by the high-speed and high-temperature spray. The morphological analysis of the powder shows that the graphene is mostly embedded in the powder, with some graphene adhering to the surfaces of the powder particles. During coating preparation, the molten, sprayed, graphene-containing particles impinge on the target surface instantaneously to form the coating, thereby ensuring that the graphene is effectively retained in the coating. There are no microcracks or voids at the interface of the coating with the substrate, which indicates that the addition of graphene does not change the structure of the coating and has little effect on the adhesive strength. 


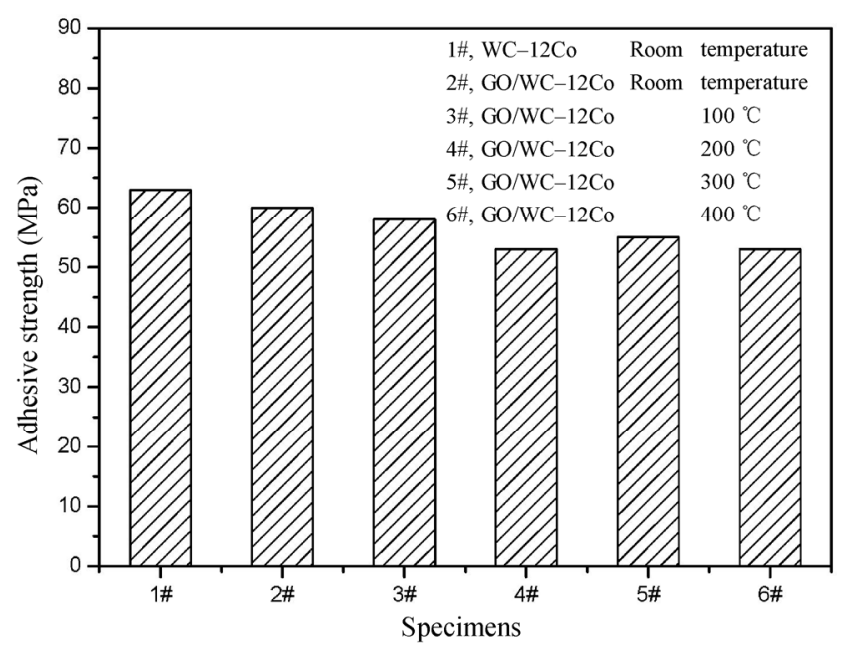

Fig. 9 Adhesive strength of the coatings prepared via different heat treatment processes.

The adhesive strengths of the graphene-modified WC-12Co coatings obtained after heat treatment at different temperatures are $58.64 \mathrm{MPa}\left(100{ }^{\circ} \mathrm{C}\right), 53.47 \mathrm{MPa}$ $\left(200{ }^{\circ} \mathrm{C}\right), 55.64 \mathrm{MPa}\left(300^{\circ} \mathrm{C}\right)$, and $53.16 \mathrm{MPa}\left(400{ }^{\circ} \mathrm{C}\right)$, indicating that the adhesive strength of the graphenemodified WC-12Co coating decreases slightly as the heat treatment temperature increases.

A tensile test analysis demonstrated adhesive fracture, indicating that a high adhesive strength is maintained inside of the coatings mainly due to the loose microstructure caused by the deposition of the small-sized particles near the surface of the coating during the spraying process. This observation indicates that the large molten sprayed particles carry high levels of energy and heat during the spraying process, and they exhibit a high degree of flattening when they make contact with the substrate. By contrast, smaller particles carry less heat and show a lower degree of flattening when they make contact with the substrate. Additionally, the heat dissipation rates from the molten droplets to the large particle structures in the surrounding deposited coating during the solidification process are low. The flattening reduces the effective contact area with the large particle structures, reduces the heat transfer between the particles inside of the coating and the adhesive fusion area, and increases the formation of pores in the coating due to the connection and packing of the particles. Therefore, the keys to ensuring a high adhesive strength of the coating are the uniformity of the particle size of the sprayed powder and the uniformity and compactness of the overall cross-sectional structure of the coating [17].

\subsection{Tribological performance analysis}

Figure 10 shows the two-dimensional macroscopic morphologies of the WC-12Co coating without graphene and the graphene-modified WC-12Co coating after undergoing wear at different temperatures, obtained using a white light interferometer. The wear track morphologies of the two coatings after undergoing room-temperature wear are similar, and the wear track in the GO/WC-12Co coating after undergoing high-temperature wear at $100{ }^{\circ} \mathrm{C}$ shows little difference. At increased wear temperatures $\left(200\right.$ and $\left.300{ }^{\circ} \mathrm{C}\right)$, the wear track in the GO/WC-12Co coating gradually widens and deepens, indicating a gradual increase in wear. By comparison, the size of the wear track formed at $400{ }^{\circ} \mathrm{C}$ is slightly decreased, while a rough peak appears at the boundary of the wear track that indicates serious wear of the coating.

Figure 11 presents a comparative analysis of the wear tracks of the coatings. For the wear tracks in the WC-12Co coating without graphene and the graphenemodified WC-12Co coating, the wear track depths are 0.817 and $0.674 \mathrm{~mm}$, respectively; the wear track
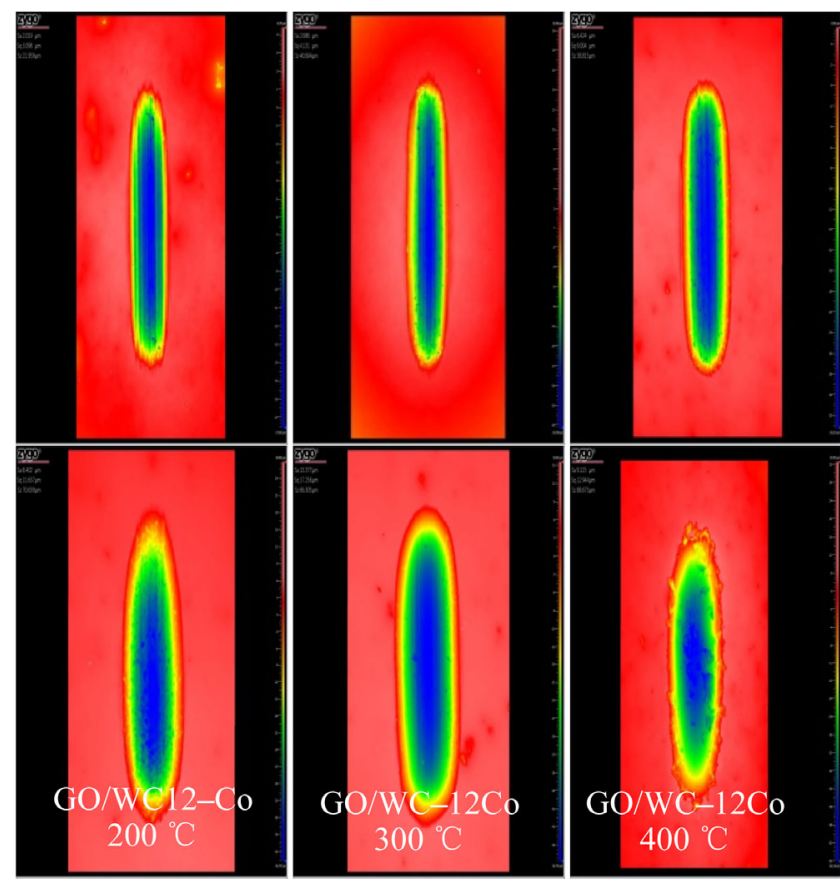

Fig. 10 Morphologies of the wear tracks in the coatings after undergoing high-temperature wear. 


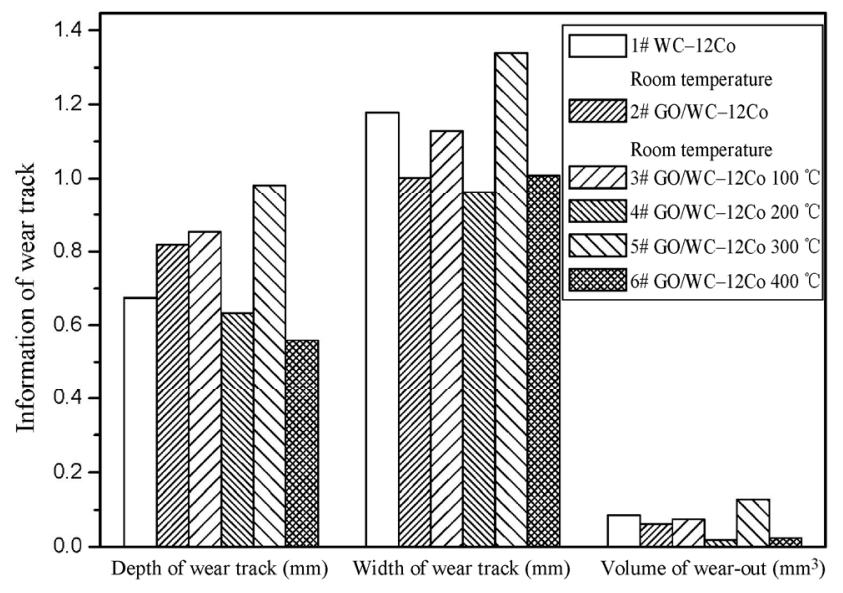

Fig. 11 Wear track properties for $\mathrm{GO} / \mathrm{WC}-12 \mathrm{Co}$ after undergoing high-temperature wear.

widths are 1.001 and $1.178 \mathrm{~mm}$, respectively; and the wear volume losses are 0.06205 and $0.08551 \mathrm{~mm}^{3}$, respectively. These results reveal that the wear performance of the coating is slightly improved after the addition of graphene.

According to the analysis of the characteristics of the GO/WC-12Co coatings that underwent different high-temperature wear processes, it was found that the high-temperature wear track formed at $300{ }^{\circ} \mathrm{C}$ has the greatest wear depth (approximately $0.981 \mathrm{~mm}$ ), while the wear track formed at $400{ }^{\circ} \mathrm{C}$ has the smallest wear depth (approximately $0.559 \mathrm{~mm}$ ). A similar analysis shows that the GO/WC-12Co coating has a large wear track width (approximately $1.339 \mathrm{~mm}$ ) after undergoing high-temperature wear at $300{ }^{\circ} \mathrm{C}$, whereas the $200{ }^{\circ} \mathrm{C}$ wear track has the smallest width (approximately $0.961 \mathrm{~mm}$ ). An analysis of the volume loss of the wear tracks shows that the volume loss of the GO/WC-12Co coating after undergoing $300{ }^{\circ} \mathrm{C}$ high-temperature wear is the largest (approximately $0.1274 \mathrm{~mm}^{3}$ ), whereas the volume loss after undergoing $200{ }^{\circ} \mathrm{C}$ wear is the smallest (approximately $0.01825 \mathrm{~mm}^{3}$ ). These results indicate that the graphene-modified WC-12Co coating shows good wear resistance while undergoing the wear process at $200{ }^{\circ} \mathrm{C}$.

Figure 12 shows the friction coefficient curves of the WC-12Co coating and the GO/WC -12 Co coatings under different temperature conditions. At the beginning of the wear process, due to the presence of microprotrusions at the wear interfaces, all coatings exhibit a short "saturation" stage, during which the wear process is not sufficiently stable and the friction coefficient increases. As the wear process continues, the coatings enter a "transition" stage, in which the value of the friction coefficient decreases slightly. Finally, the wear process becomes stable, and the coefficients of friction tend to stabilize with no big change [18]. The WC-12Co coating with no graphene (curve \#1) has the highest coefficient of friction, which gradually stabilizes at a value of approximately 0.6 after $200 \mathrm{~s}$ of wear. By contrast, for the GO/WC-12Co coating at $400{ }^{\circ} \mathrm{C}$ (curve \#6), the friction coefficient increases sharply during the initial stage to approximately 0.7 and then gradually stabilizes after a long time (500 s). After this point, the friction coefficient changes in a smooth manner throughout the wear process, stabilizing at approximately 0.5 . Similarly, the friction coefficient of the GO/WC-12Co coating at $200{ }^{\circ} \mathrm{C}$ (curve \#4) becomes stabile during the wear process, although it exhibits a slight increase toward the end of the process, stabilizing at an average value of 0.35 . Additionally, the friction coefficients of the GO/WC-12Co coating at room temperature, $100{ }^{\circ} \mathrm{C}$, and $300{ }^{\circ} \mathrm{C}$ are similar (approximately 0.3). However, these coefficients differ as at $300{ }^{\circ} \mathrm{C}$, the coefficient fluctuates greatly throughout the entire wear process. A comprehensive comparison shows that the friction coefficient of the graphenemodified WC-12Co coating is reduced by nearly $50 \%$ compared with that of the WC-12Co coating at room temperature. The friction coefficient of the $\mathrm{GO} / \mathrm{WC}-12 \mathrm{Co}$ coating under high temperature conditions (100 and $300{ }^{\circ} \mathrm{C}$ ) can still be maintained at approximately 0.3 .

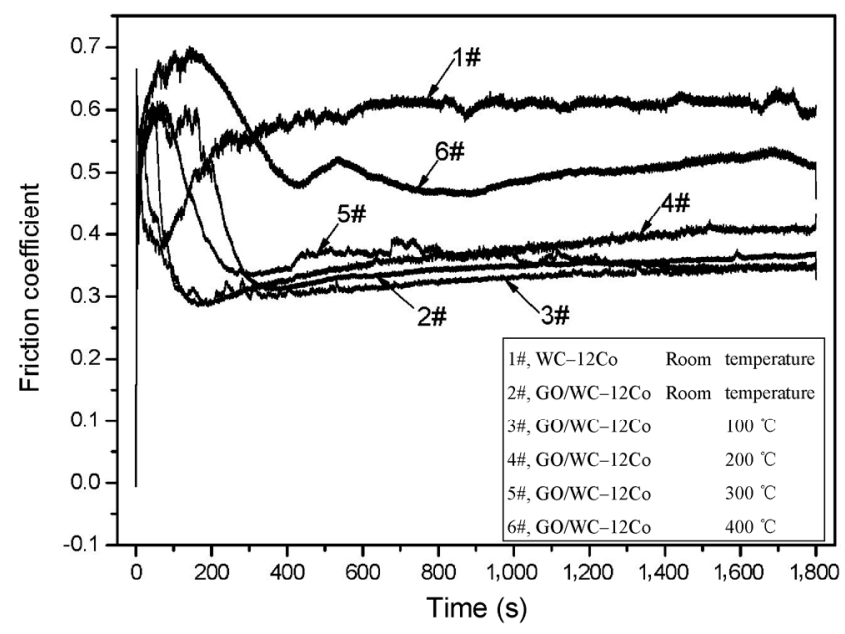

Fig. 12 Friction coefficients of the coatings at high temperatures. 
At $400{ }^{\circ} \mathrm{C}$, the friction coefficient increases to 0.5 but is still lower than the friction coefficient of the original WC-12Co coating, indicating that addition of graphene leads to an increase in the friction reduction ability of the coating under both room-temperature and high-temperature conditions.

\subsection{High-temperature wear resistance and the self- lubricating mechanisms of graphene}

The wear track morphologies of the coatings with and without graphene modification were analyzed, as shown in Fig. 13(a). The surface of the WC-12Co coating without graphene is rough after undergoing wear at room temperature, and many pits caused by the peeling of the wear debris are observed. This peeling occurs as during the wear process, the wear

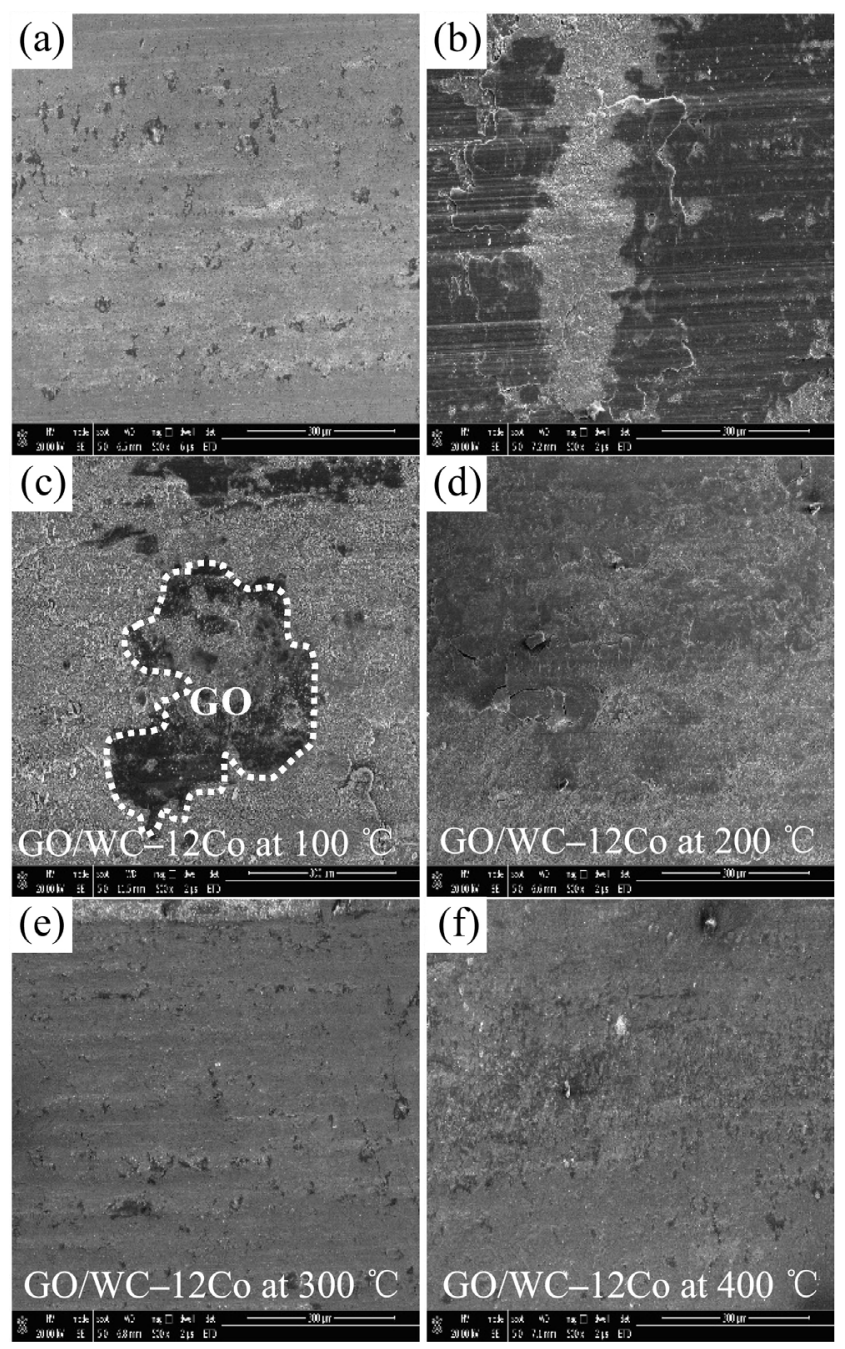

Fig. 13 Macromorphologies of the wear tracks in the coatings after undergoing high-temperature wear. debris, coating, and friction materials are all in the same plane, and their probabilities of bearing the load are therefore the same. Aggregated block-shaped wear debris slides along the tangential direction of the wear track surface due to the action of the friction pair, forming a deep furrow. The coating undergoes extrusion deformation under continuous reciprocating rolling, thereby repeatedly generating wear debris, which intensifies the wear of the coating. Therefore, the WC-12Co coating undergoes a typical combination of fatigue wear and abrasive wear [19].

Figures 13(b) and 13(c) show the wear track morphologies of the graphene-modified WC-12Co coating formed during wear at room temperature and $100{ }^{\circ} \mathrm{C}$, respectively. A large area of transparent black material covers the wear track surface. As the wear process progresses, the amount of this black transparent material that is present on the wear track surface gradually increases. This indicates that the thinlayered structure of the graphene is not deformed or denatured during the spraying process, and the graphene will gradually adhere to form a discretely distributed lubricating film during wear [20].

Figure 13(d) presents the wear track formed in the graphene-modified WC-12Co coating during wear at $200{ }^{\circ} \mathrm{C}$. Although a small amount of wear debris can be seen adhering to the surface of the wear track, the wear track is relatively flat and smooth with no obvious furrows or deep scratches. This observation indicates that the coating produces little wear debris, thereby reducing the "three-body" wear between the elements of the friction pair due to wear debris scratching the wear surface [21]. The coating has a high hardness while also having an appropriate toughness. Additionally, a black substance with a uniform and discrete distribution in the friction direction is embedded in the surface of the wear track, as was observed in microareas under high magnification.

Figures 13(e) and 13(f) show the wear track morphologies of the graphene-modified WC $-12 \mathrm{Co}$ coating formed during wear at 300 and $400{ }^{\circ} \mathrm{C}$, respectively. In each case, the surface of the entire wear track is dark gray in color. Many protruding particles can be seen on the surface of the wear track. These particles are surrounded by a grayish-white flaking area, which corresponds to the peeling of the 
wear debris accumulated during the wear process when long-distance sliding does not occur.

Figure 14 displays the local micromorphologies of the wear tracks in the coatings with and without graphene modification. Figure 14(a) shows the wear track morphology of the WC-12Co coating without graphene formed during wear at room temperature. A large area of peeling, i.e., pits left after the granular wear debris has peeled off from the surface of the coating, can be seen on the surface of the wear track. Local microscopic analysis shows that the wear track structure is either loose or contains microcracks. This phenomenon occurs because of the formation of dense through-cracks between the peeling-induced pits. The connections between these peeling-induced pits cause the coating structure to be further crushed. The results
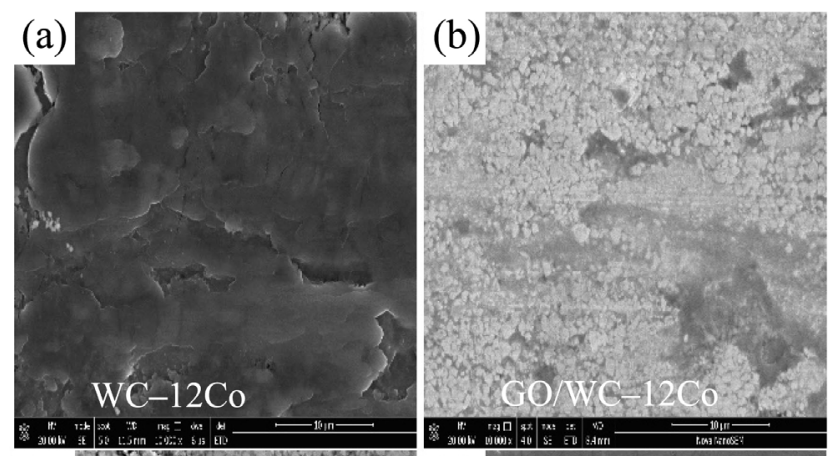

(c)
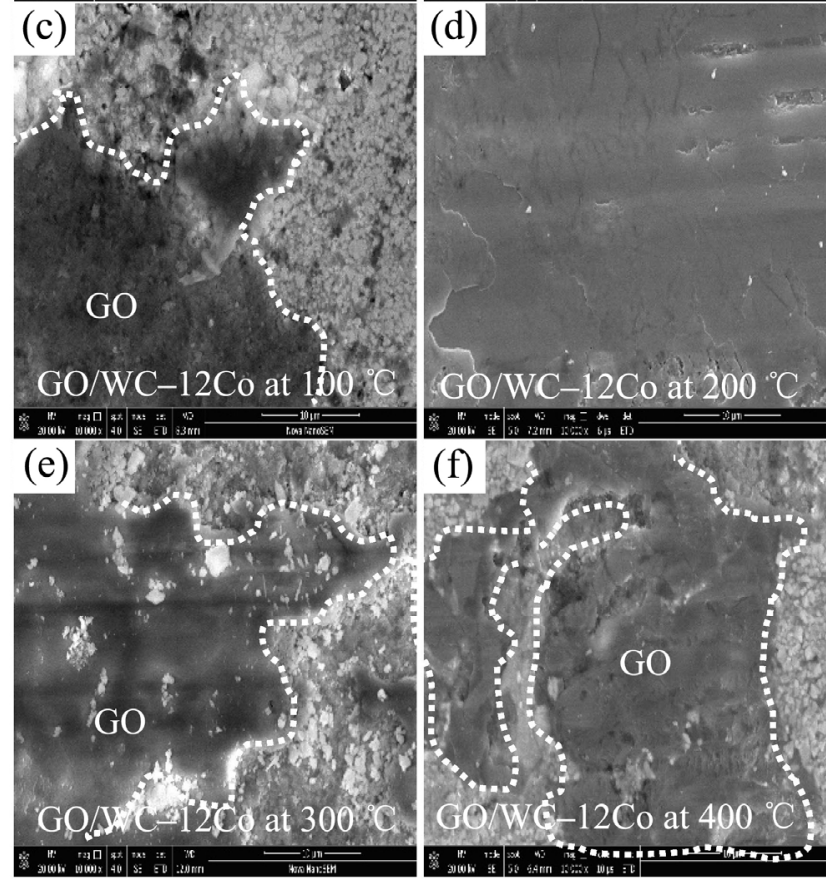

Fig. 14 Micromorphologies of the wear tracks in the coatings after undergoing high-temperature wear. in the generation of microcracks, which eventually lead to the increased generation of wear debris and the brittle peeling of the coating.

Figure 14(b) shows the morphology of the wear track in the graphene-modified WC-12Co coating after undergoing wear at room temperature. The large-area black graphene film, which has good self-lubricating and antifriction effects, almost completely covers the surface of the wear track, confirming the low friction coefficient observed under this condition (approximately 0.3 ; Fig. 11, curve \#2). It can also be seen from the boundary of the graphene film that graphene from the inside of the structure becomes exposed on the surface of the wear track during the wear process. As the graphene undergoes repeated rolling compression, it spreads to cover the protrusions. Observation of the high-magnification structure of a microarea confirms that the transparent graphene covers the surface of the aggregated wear debris.

Significantly different from the graphene film on the surface of the wear track in Fig. 14(b), the local morphology of the wear track in the graphenemodified WC-12Co coating after undergoing wear at $100{ }^{\circ} \mathrm{C}$ is shown in Fig. 14(c). Here, the graphene film is relatively isolated, and the wear track structure is dense and complete. The mechanism by which this occurs is that GO, as a type of sheet-like nanofiller with extremely high mechanical strength, improves the strength of the coating, thereby reducing the possibility of the fatigue wear of the coating, as well as the generation of peeling pits and wear debris [20, 21]. The friction coefficient is confirmed to be low under this condition (approximately 0.3; Fig. 12, curve \#3).

Figure 14(d) shows the local micromorphology of the wear track formed in the graphene-modified WC -12 Co coating at $200{ }^{\circ} \mathrm{C}$. The surface of the wear track is flat and smooth, with almost no visible friction furrows, and the graphene film has high integrity. This result is also consistent with the low friction coefficient observed under this condition (approximately 0.35; Fig. 12, curve \#4).

Figure 14(e) shows the local morphology of the wear track formed in the graphene-modified WC-12Co coating at $300{ }^{\circ} \mathrm{C}$. The graphene film is relatively isolated, and the graphene and WC-12Co particles in adjacent regions are clearly separated. In particular, 
the microstructure of the wear track formed at $300{ }^{\circ} \mathrm{C}$ is loose, with clear granular adhesion and high porosity, which corresponds to the weak areas in the coating where brittle peeling occurs. Accompanied by shearing and an increase in pressure during the wear process, peeling of the graphene sheets occurs in the coating; this observation is consistent with the large fluctuations in the coefficient of friction observed throughout the entire wear process under this condition (Fig. 12, curve \#5).

Figure 14(f) shows the morphology of the wear track formed in the graphene-modified WC-12Co coating at $400{ }^{\circ} \mathrm{C}$. The graphene film shows relatively low integrity, with little graphene aggregation and the local appearance of a few microcracks in the wear track. This observation indicates that the brittle peeling of the coating causes the wear of the particles, which is consistent with the relatively high friction coefficient observed under this condition (approximately 0.5; Fig. 12, curve \#6).

Figure 15 presents a microarea analysis of the wear tracks formed in the graphene-modified WC-12Co coating under high-temperature conditions. In Figs. 15(a)-15(d), the wear track surfaces clearly show dark black sheet-like GO films on the WC-12Co-coated substrates, wherein the thicknesses of the GO films are in the order of nanometers. A large amount of embedded graphene is distributed in the coating and is continuously exposed at the surface of the wear track during the wear process. Because of the characteristics of its carbonaceous single-layer atomic structure, which enables lubrication of the friction pair, the graphene causes large slippage between the elements of the friction pair during the wear process. This also improves the self-lubricating property of the coating itself by reducing biting and grinding between the friction pair elements. This phenomenon plays an extremely beneficial role in self-lubrication and wear resistance, further indicating that the structural compactness and graphene content of the coating are closely related to the self-lubricating properties of the coating.

Raman spectroscopy analysis was performed on the microarea labeled as Zone A in Fig. 15(a). As shown in Fig. 16, D and G peaks appear at 1,350 and $1,605 \mathrm{~cm}^{-1}$, respectively, and the intensity of the D peak
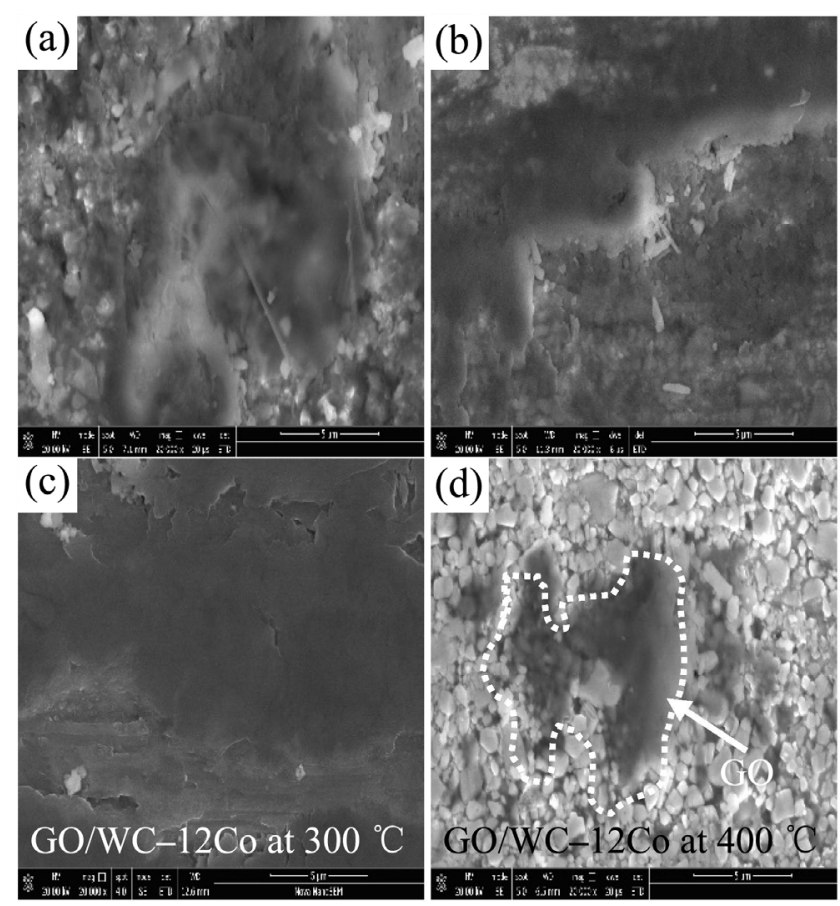

Fig. 15 Graphene in wear tracks formed in the $\mathrm{GO} / \mathrm{WC}-12 \mathrm{Co}$ coatings during high-temperature wear.

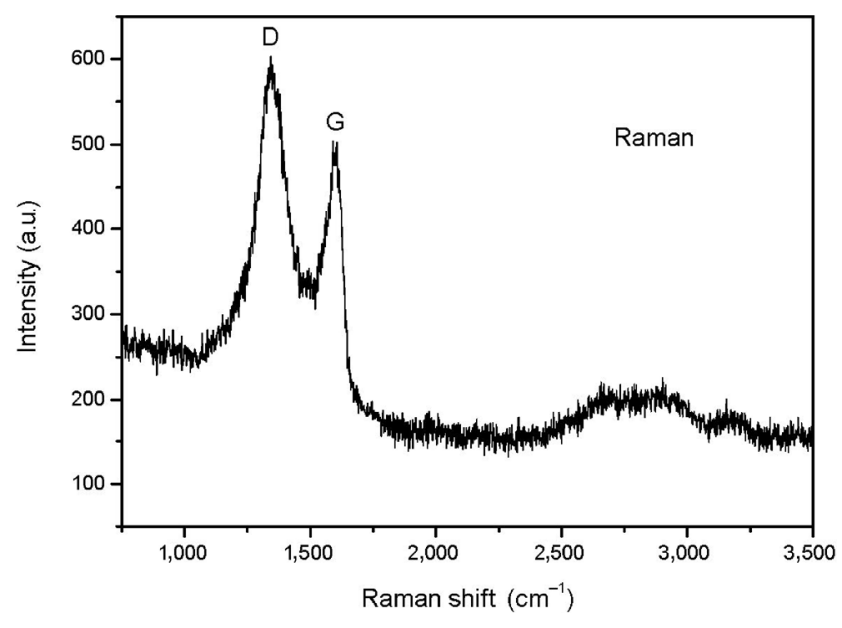

Fig. 16 Raman analysis of the graphene in a wear track of a $\mathrm{GO} / \mathrm{WC}-12 \mathrm{Co}$ coating.

is higher than that of the G peak, which are typical characteristics of GO peaks [15].

The self-lubricating wear-resistance mechanism of the graphene-modified WC coatings can be described as follows. The friction and resulting frictional heat become increasingly pronounced as the wear process progresses, and the WC in the coating becomes worn. The GO wrapped around or embedded in the WC is gradually exposed and distributed on the surface of the wear track, forming a nanoscale GO transfer film. 
During the wear process, relative sliding between the GO sheets occurs in place of the relative sliding of the friction pair formed by the metal surfaces, thereby achieving separation between the wear debris and the surfaces of the friction pair elements. The selflubricating, wear-reducing, and antiwear effects of this coating is therefore achieved, and the wear resistance of the coating is improved with the use of graphene [19].

In summary, compared with the friction coefficient of the WC-12Co coating without graphene (approximately $0.6)$, the friction coefficient of the graphene-modified WC -12 Co coating is reduced by $50 \%$ at room temperature. Moreover, the graphene-modified coating maintains good self-lubricating and antifriction effects at 100 and $200{ }^{\circ} \mathrm{C}$, as the friction coefficient is maintained at 0.3 . During wear at $300{ }^{\circ} \mathrm{C}$, the friction coefficient fluctuates greatly, and the graphene film formed on the wear track surface is not sufficiently continuous, resulting in a loose WC-12Co structure in the adjacent area. During wear at $400{ }^{\circ} \mathrm{C}$, the friction coefficient increases to 0.5 , the amount of graphene film aggregating on the wear track surface is less than that at observed at other temperatures, and a small number of microcracks appear in the wear track, indicating abrasive wear caused by brittle peeling of the coating. This observation indicates that the coating structure undergoes a certain amount of oxidation during the high-temperature wear process, as the presence of pores cause portions of the coating structure to peel off, resulting in abrasive wear occurs. In general, the addition of graphene provides beneficial self-lubricating and antiwear capabilities, which are closely related to the ability to achieve effective coating of the spray powder material with graphene. Due to its extremely large specific surface area and high activity, nanoscale graphene will typically aggregate into graphite powder during ball milling, completely destroying the original nanolayer structure of the graphene and resulting in the loss of its self-lubricating properties. However, in the wet ball milling process used in this study, ultrasonic dispersion technology is first applied to shake, crush, and mix the graphene in a liquid medium to form a liquid graphene mixture. Then, mechanical force is applied in the ball milling process to achieve even adhesion of the graphene on the surfaces of the powder particles. The subsequent spray granulation process involves directly mixing graphene and WC-12Co spray powder with a binder. The graphene can be uniformly and extensively coated on the surfaces of the powder particles while maintaining its thin-layer structure. Therefore, the effective combination of the graphene and spray powder during the powder preparation process is the key to successful coating preparation.

Moreover, the spraying process determines the final structure of the coating, which, in turn, affects the wear resistance and retention of the graphene in the coating. In the graphene-modified WC-12Co mixed powder, the graphene adheres to the surfaces of the WC-12Co particles or is embedded in the crevices of the particles, which is equivalent to mechanical bonding of the graphene to the particles. D-gun spraying technology has several advantages [12]. First, the available temperature range of the spray beam is large $\left(300-2,000{ }^{\circ} \mathrm{C}\right)$; second, the spraying process consists of pulsed spot spraying; and third, the beam speed during the spraying process is high $(700-1,000 \mathrm{~m} / \mathrm{s})$. By adjusting the process parameters and selecting the appropriate spray temperature, it is possible to ensure that the graphene adhered to the WC-12Co particle surfaces in the spray beam will not be oxidized by the high temperature. Additionally, appropriate spray speed control should be employed to ensure that the graphene adhered to the WC-12Co particle surfaces is not blown away and that the graphene content in the coating is therefore maximally retained. In this way, a discrete and uniform distribution of the graphene in the graphene-modified, self-lubricating, and wearresistant coating can be obtained, which ensures not only that the physical state of the graphene remains unchanged, but also the maximum retention of the graphene that was originally added to the coating is achieved.

\section{Conclusions}

1) Wet ball milling and spray granulation mixing processes were used to obtain a composite graphene/ WC-12Co powder that enabled uniform and close adhesion of the graphene onto the surfaces of the powder particles. The prepared graphene largely covered the surfaces of the WC-12Co particles, and the prepared composite powder exhibited good sphericity, 
flowability, and particle size uniformity.

2) The graphene-modified, self-lubricating, and wearresistant WC-12Co coating prepared via D-gun spraying technology possessed a dense structure with a porosity of approximately $1.41 \%$. The graphene was embedded in the coating structure, and the number of layers of graphene sheets was approximately 7 to 10 . Moreover, the transparent thin-layer structure of the graphene remained unchanged.

3) The addition of graphene had little effect on the adhesive strength and hardness of the WC-12Co coating. After high-temperature treatment, the adhesive strength and hardness of the graphene-modified WC12Co coating were slightly reduced.

4) In contrast to the WC-12Co coating without graphene, which has a friction coefficient of approximately 0.6 , the graphene-modified WC-12Co coating formed a graphene transfer film on the wear track surface. This film provides self-lubricating antiwear and wear-resistant properties to the surface, thereby improving the wear resistance of the coating. At room temperature, the friction coefficient was reduced by $50 \%$. At 100 and $200{ }^{\circ} \mathrm{C}$, the graphene still exhibited good self-lubricating and antifriction properties, and the friction coefficient of the coating was maintained at 0.3 .

\section{Acknowledgements}

This project was sponsored by the National Natural Science Foundation of China (51605455).

Open Access This article is licensed under a Creative Commons Attribution 4.0 International License, which permits use, sharing, adaptation, distribution and reproduction in any medium or format, as long as you give appropriate credit to the original author(s) and the source, provide a link to the Creative Commons licence, and indicate if changes were made.

The images or other third party material in this article are included in the article's Creative Commons licence, unless indicated otherwise in a credit line to the material. If material is not included in the article's Creative Commons licence and your intended use is not permitted by statutory regulation or exceeds the permitted use, you will need to obtain permission directly from the copyright holder.
To view a copy of this licence, visit http://creativecommons.org/licenses/by/4.0/.

\section{References}

[1] Novoselov K S, Geim A K, Morozov S V, Jiang D, Zhang Y, Dubonos S V, Grigorieva I V, Firsov A A. Electric field effect in atomically thin carbon films. Science 306(5696): 666-669 (2004)

[2] Pu J B, Wang L P, Xue Q J. Progress of tribology of graphene and graphene-based composite lubricating materials. Tribology 34(1): 93-112 (2014)

[3] Li J F, Zhang L, Xiao J K, Zhou K C. Sliding wear behavior of copper-based composites reinforced with graphene nanosheets and graphite. Trans Nonferrous Met Soc China 25(10): 3354-3362 (2015)

[4] Ye X Y, Liu X H, Yang Z G, Wang Z F, Wang H G, Wang J Q, Yang S R. Tribological properties of fluorinated graphene reinforced polyimide composite coatings under different lubricated conditions. Compos Part A Appl Sci Manuf 81: 282-288 (2016)

[5] Dong S Y, Xu B S, Wang Y J, Wei S C. Surface science and technology on preparation and applications of graphene. China Surf Eng 26(6): 1-8 (2013)

[6] Rutkowski P, Stobierski L, Zientara D, Jaworska L, Klimczyk P, Urbanik M. The influence of the graphene additive on mechanical properties and wear of hot-pressed $\mathrm{Si}_{3} \mathrm{~N}_{4}$ matrix composites. J Eur Ceram Soc 35(1): 87-94 (2015)

[7] Piao Z Y, Zhou Z Y, Xu J, Wang H D. Use of X-ray computed tomography to investigate rolling contact cracks in plasma sprayed Fe-Cr-B-Si coating. Tribol Lett 67(1): 11(2019)

[8] Zhang J, Piao Z Y, Deng L J, Zhang S, Liu J. Influence of pin assembly on the wear behavior of piston skirt. Eng Failure Anal 89: 28-36(2018)

[9] Min C Y, Nie P, Liu Y, Shen D, Zeng M, Li N. Preparation and tribological properties of high temperature resistance graphene oxide/polyimide nanocomposites. J Solid Rocket Technol 37(4): 569-573 (2014)

[10] Piao Z Y, Xu B S, Wang H D, Yu X X. Rolling contact fatigue behavior of thermal-sprayed coating: A review. Crit Rev Solid State Mater Sci, DOI 10.1080/10408436.2019.1671798.

[11] Yuan J H, Zhu Y C, Lei Q, Zhan Q, Huang J, Ding S Y. Fabrication and high temperature tribological properties of plasma sprayed WC-Co-Cu-BaF $2 / \mathrm{CaF}_{2}$ self-lubricating wear resistant coatings. China Surf Eng 25(2): 31-36 (2012)

[12] Wang T G, Li B S, Yan B, Fan Q X, Liu Y M, Gong J, Sun C. Tribological behavior of multi-layered $\mathrm{WC}-\mathrm{Co} / \mathrm{MoS}{ }_{2}-\mathrm{Ni}$ 
self-lubricating coating fabricated by detonation gun spraying. J Mater Eng 45(3): 73-79 (2017)

[13] Li R, Lu T Y. The influence of carbon nanotubes and graphene as additives in lubricant oil on friction and wear. China Sciencepaper 10(10): 1123-1126 (2015)

[14] Zhang J, Piao Z Y, Liu S Y. Influence of skirt profile structure of gasoline engine piston on the friction and wear characteristics under standard conditions. J Tribol 140(2): 021703 (2018)

[15] Liu C S, Su F H, Liang J Z. Producing cobalt-graphene composite coating by pulse electrodeposition with excellent wear and corrosion resistance. Appl Surf Sci 351: 889-896 (2015)

[16] Chen J J, Li J L, Xiong D S, He Y, Ji Y J, Qin Y K. Preparation and tribological behavior of Ni-graphene composite coating under room temperature. Appl Surf Sci 361: 49-56 (2016)

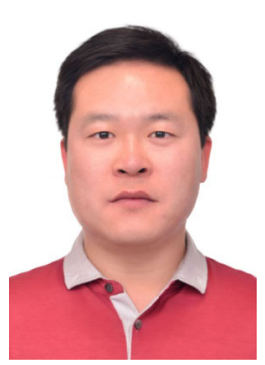

Haoliang TIAN. He graduated from Beijing University of Aeronautics and Astronautics with a doctor's degree and now works in the Institute of surface engineering, Beijing Institute of aeronautical materials, AVIC, China. He is a

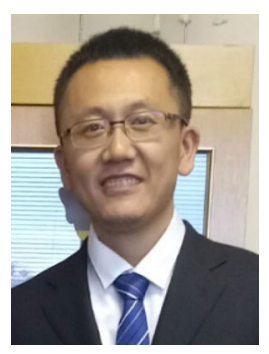

Changliang WANG. He graduated from Beijing University of Aeronautics and Astronautics with a master's degree and now works in the Surface Engineering Research Institute of Beijing Institute of aeronautical materials, AVIC, China.

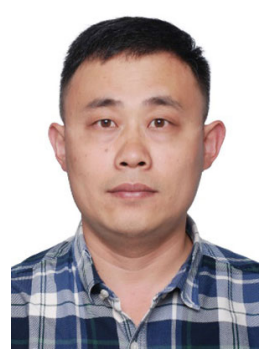

Mengqiu GUO. He graduated from Beijing University of Aeronautics and Astronautics with a master's degree and now works in the Surface Engineering Research Institute of Beijing Institute of aeronautical
[17] Zhang Q, Diao D F. Potential of graphene layer controlling nano-wear during $\mathrm{C}_{60}$ intrusion by molecular dynamics simulation. Wear 306(1-2): 248-253 (2013)

[18] Li H Q, Xie Y T, Li K, Huang L P, Huang S S, Zhao B Z, Zheng X B. Microstructure and wear behavior of graphene nanosheets-reinforced zirconia coating. Ceram Int 40(8): 12821-12829 (2014)

[19] Algul H, Tokur M, Ozcan S, Uysal M, Cetinkaya T, Akbulut $\mathrm{H}$, Alp A. The effect of graphene content and sliding speed on the wear mechanism of nickel-graphene nanocomposites. Appl Surf Sci 359: 340-348 (2015)

[20] Jia Z F, Pang X J, Li H Y, Ni J J, Shao X. Synthesis and wear behavior of oleic acid capped calcium borate/graphene oxide composites. Tribol Int 90: 240-247 (2015)

[21] Berman D, Erdemir A, Sumant A V. Reduced wear and friction enabled by graphene layers on sliding steel surfaces in dry nitrogen. Carbon 59: 167-175 (2013)

senior engineer, mainly engaged in the material design, structural design, and process optimization of thermal spray wear-resistant coating and thermal protective coating for key components of aeroengine, focusing on the research of coating service mechanism and reliability improvement.

He is a senior engineer, mainly engaged in the research and development of high temperature resistant selflubricating coating materials for key components of aeroengine, process optimization, and research on the mechanism of high temperature resistant selflubricating and wear-resistant coating.

materials, AVIC, China. He is a senior engineer, mainly engaged in the research and development of hightemperature abradable coating materials for key components of aeroengine, surface texture, spray process optimization and coating abradable mechanism. 


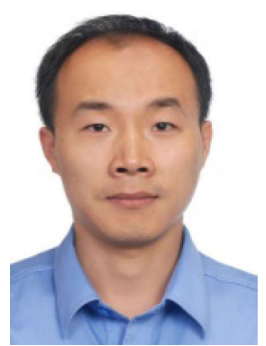

Yongjing CUI. He graduated from Beijing University of Aeronautics and Astronautics with a master's degree and now works in the Surface Engineering Research Institute of Beijing Institute of aeronautical

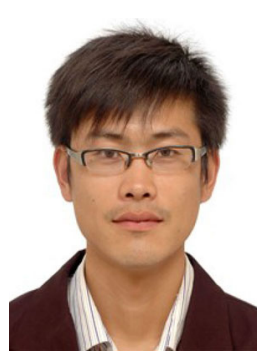

Junguo GAO. He graduated from Beijing University of Science and Technology with a doctor's degree and now works in the Surface Engineering Research Institute of

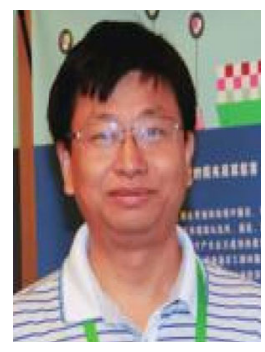

Zhihui TANG. He is a director and a researcher. He graduated from University of Science and Technology of China with a master's degree and now works in Surface Engineering Research Institute of materials, AVIC, China. He is a senior engineer, mainly engaged in the research and development of anti-scour coating material of resin matrix composite for aeroengine, the development of explosion spraying technology, and the research of service behavior of coating.

Beijing Institute of aeronautical materials, AVIC, China. $\mathrm{He}$ is a senior engineer, mainly engaged in the research and development of sealing/superhydrophobic coating materials, structural design, and coating service behavior for aeroengine.

Beijing Aeronautical Materials Research Institute of China Aviation Development Corporation, China. He is a senior engineer, mainly engaged in the research and development of anti-corrosion coating materials, structural design, coating corrosion behavior, and corrosion mechanism for aeroengine. 